\title{
Preparation and Characterization of Nanowhiskers Cellulose from Fiber Arrowroot (Maranta arundinacea)
}

\author{
Renato Mariano de Sáa ${ }^{*}$, Cleidiene Souza de Miranda ${ }^{a}$, Nadia Mamede José ${ }^{a}$ \\ ${ }^{a}$ Programa de Pós-graduação de Engenharia Química, Instituto de Química, \\ Universidade Federal da Bahia - UFBA, Rua Barão de Jeremoabo, 147, \\ $2^{\circ}$ andar, sala 215, Ondina, CEP 40210-630, Salvador, BA, Brazil
}

Received: December 14, 2014; Revised: November 18, 2015

\begin{abstract}
The agribusiness generates countless sources of biomass that are not appropriately and / or adequately utilized, turning them into industrial wastes. This study aims to explore the Arrowroot fiber as a source of raw material for the cellulose nanowhiskers production by acidic hydrolysis. Hydrolyses were carried out varying the temperature and the sulfuric acid concentration, with the hydrolysis reaction time fixed and constant stirring. The nanowhiskers of cellulose extracted from the arrowroot fibers has great potential as reinforcing agents in the nanocomposites production regarding to others cellulose nanowhiskers sources, because they have shown a similar performance as the other fibers, good thermal stability, crystallinity index and good aspect ratio as compared to the literature.
\end{abstract}

Keywords: nanowhiskers, arrowroot, cellulose, acid hydrolysis

\section{Introducion}

Brazil for being a country with a large agribusiness produces agricultural industries residues that cause environmental impact and, then, the search for alternatives to the use of organic matter generated grows in several research centers. Producers and industries are facing the problem of the residual biomass disposal, although it is biodegradable, it needs a minimum time to be mineralized, becoming a source of environmental pollutants. Such agribusiness residues contain several biologically active substances that are wasted ${ }^{1}$.

Lignocellulosic fibers are excellent raw materials for the chemistry of polymers and composites, which can be proven by the high number of patents and national and international articles, besides the large number of products already marketed ${ }^{2-7}$.

The arrowroot is attracting interests of the industries that produce starch in Brazil against reports of differentiated properties of that starch in bakery products. It is a root from Latin America and it is native from Venezuelan forests ${ }^{8}$.

The rhizomes of arrowroot cultivated in Venezuela presented $5.46 \%$ of protein, $5.96 \%$ of grease matter, $2.84 \%$ of ash, $7.49 \%$ of cellulosic fibers, $78.25 \%$ of total carbohydrates (expressed on a dry basis), $79.88 \%$ of humidity and $\mathrm{pH}$ of $6.9^{99]}$.

Recent interest in the use of rigid nanoscale particles as reinforcing materials in polymeric matrices, composites or nanocomposites, has increased. Two good examples of these types of particles are the carbon nanotubes and cellulose nanowhiskers ${ }^{10}$.

In that context the use of arrowroot fibers is biomass residues originated from the agribusiness, which present good source to obtain the cellulose nanowhiskers.

*e-mail: renato_msa@yahoo.com.br

\section{Material and Methods}

Arrowroot fibers used in this study were donated by farmers from the town of Cruz das Almas, Bahia, Brazil. The fibers already came previously extracted from rhizomes arrowroot, after being dried were triturated in a mill type Willye TE-680, and then treated by the following processes.

Process for Extraction of lignin and hemicellulose: $10 \mathrm{~g}$ of arrowroot fiber were placed in $200 \mathrm{ml}$ of sodium hydroxide solution at $5 \%$ in a beaker with mechanical agitation, for 2 hours at a temperature of $80^{\circ} \mathrm{C}$. Then they were filtered under vacuum, washed with distilled water and dried at a temperature of $70^{\circ} \mathrm{C}$ in a stove ${ }^{11}$.

Bleaching of fibers with Sodium Hypochlorite: After the extracting lignin process, $5 \mathrm{~g}$ of the treated fiber were submitted to a solution of $200 \mathrm{ml}$ of sodium hypochlorite (2.5\%) and a buffer solution 1:1 (acetic acid (5\%) and sodium hydroxide $(5 \%)$, for 2 hours at $80^{\circ} \mathrm{C}$ until bleaching ${ }^{12}$. Subsequently they were filtered under vacuum, washed with distilled water and dried in a stove at $70^{\circ} \mathrm{C}$.

Preparation of the Nanowhiskers: After bleaching the fibers were four separate samples realization to acid hydrolysis, where four concentrations of sulfuric acid and two temperature conditions were used, with the time and the fiber mass fixed, for conducting the acid hydrolysis in a beaker with mechanical agitations seen in Table 1 .

Thermal stabilities of samples were determined using Shimadzu TGA-50 equipment. The analysis conditions were: a nitrogen atmosphere with flow $50 \mathrm{~mL} \mathrm{~min}^{-1}$, heating rate of $20^{\circ} \mathrm{C} \mathrm{min}-1$ and temperature range from 25 to $1000{ }^{\circ} \mathrm{C}$. The diffractograms were obtained on $\mathrm{X}$ ray diffractometer, Shimadzu model XRD-6000 with angles $2 \theta$ between 5 and $80 \theta$. The chemical structure of the samples was analyzed using 
FTIR Shimadzu model IR Prestige-21. The Scanning Electron Microscope JEOL 6390LV used.

\section{Results and Discussion}

Figure 1 show the thermal profile of the fiber in natura (FNAT), bleached fiber (FBRA) and the nanowhiskers obtained on the four conditions of acid hydrolysis.

Based on the thermogravimetric analysis the following parameters were estimated: initial temperature of thermal degradation $\left(\mathrm{T}_{\text {on set }}\right)$, humidity content $(\%)$, residue content (\%), Table 2 .

It can be observed from Figure 1a and Table 2 that the starting temperature of the thermal degradation of the obtained cellulose nanowhiskers were closed to the four acid hydrolysis conditions used. The fiber in nature (FNAT) showed a higher initial thermal degradation due to the presence of the fiber constituents that serve as barriers to initiate its degradation, but the other samples are most exposed due to the efficiency of the steps that leading up to acid hydrolysis for nanowhiskers extracting. Samples
NA01, NA02 and NA03 showed a higher residue rate, and it can be attributed to the formation of a carbon layer on the cellulose surface which can act as a barrier.

In Figure 1b, the curve of bleached fiber (FBRA) presented two events that can be attributed to the presence of hemicellulose and cellulose, where it shows an overlay on the starting of the initial temperature of thermal degradation of one with the end of the other.

The crystal structure of the fiber in nature (FNAT), bleached fiber (FBRA) and obtained cellulose nanowhiskers were studied by DRX as shown in Figure 2.

It is observed that in all the profiles of difratogram, there is a peak at $2 \theta$ equal to $22.7^{\circ}$ (002 plane) and $16^{\circ}$ (101 plane), characteristic of cellulose type $I^{[13,14]}$, referent the crystalline base of the unit cell found in cellulosic fibers. However, the original crystalline structure of cellulose, the mechanical strength has been maintained in nanowhiskers after acid hydrolysis.

Crystallinityindex $\left(\mathrm{I}_{c}\right)$ was calculated by $\mathrm{I}_{\mathrm{c}=}\left[\mathrm{I}_{(002)-} \mathrm{I}_{(\mathrm{am})} \mathrm{I}_{(002)}\right] \times 100$, where, $I_{(002)}$ is the intensity corresponding to the peak of crystalline material $\left(2 \Theta=22^{\circ}\right), \mathrm{I}_{(\mathrm{am})}$ is the intensity event of

Table 1. Acid hydrolysis conditions for nanowhiskers obtaining.

\begin{tabular}{cccccc}
\hline Sample & Mass $(\mathbf{g})$ & $\begin{array}{c}\text { Volume of } \mathbf{H}_{\mathbf{2}} \mathbf{S O}_{\mathbf{4}} \\
(\mathbf{m L} \mathbf{)}\end{array}$ & $\begin{array}{c}\text { Concentration } \\
\mathbf{H}_{\mathbf{2}} \mathbf{S O}_{\mathbf{4}}(\mathbf{\%})\end{array}$ & $\begin{array}{c}\text { Temperature }\left({ }^{\circ} \mathbf{C}\right) \\
\text { Time }(\mathbf{m i n u t e s})\end{array}$ \\
\hline NA01 & 5 & 100 & 55 & 65 & 105 \\
NA02 & 5 & 100 & 60 & 65 & 105 \\
NA03 & 5 & 100 & 55 & 55 & 105 \\
NA04 & 5 & 100 & 60 & 55 & 105 \\
\hline
\end{tabular}

Table 2. Thermal analysis values.

\begin{tabular}{cccccc}
\hline Sample & $\mathbf{T}_{\text {on set }}\left({ }^{\circ} \mathbf{C}\right)$ & Humidity (\%) & Residue (\%) & $\mathbf{I}_{\mathbf{C}}(\mathbf{\%})$ & Yield (\%) \\
\hline FNAT & 268 & 14 & 16 & 23 & - \\
FBRA & 210 & 9 & 16 & 56 & - \\
NA01 & 243 & 6 & 27 & 47 & 33 \\
NA02 & 244 & 8 & 21 & 56 & 20 \\
NA03 & 242 & 9 & 20 & 61 & 30 \\
NA04 & 243 & 8 & 13 & 64 & 30 \\
\hline
\end{tabular}

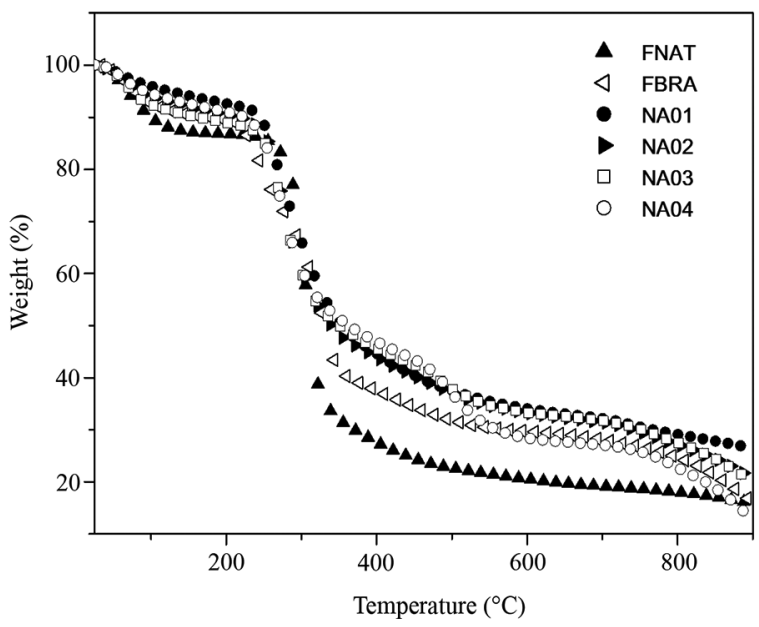

(a)

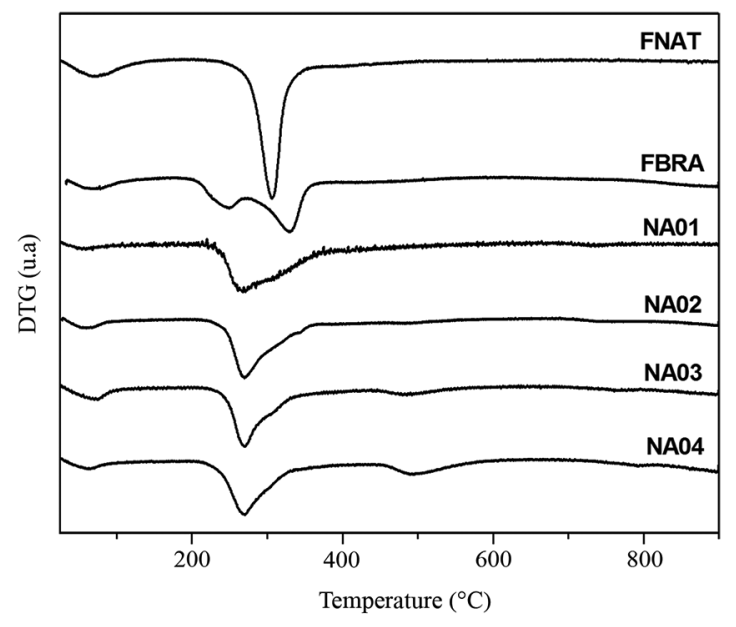

(b)

Figure 1. TG curves (a) and DTG (b) of the fiber in nature, bleached fiber and the cellulose nanowhiskers obtained. 
amorphous materials $\left(2 \Theta=16^{\circ}\right)^{[15]}$. The results are shown in Table 2.

The results showed that the fiber treatment was effective for amorphous part removal in the steps leading up to acid

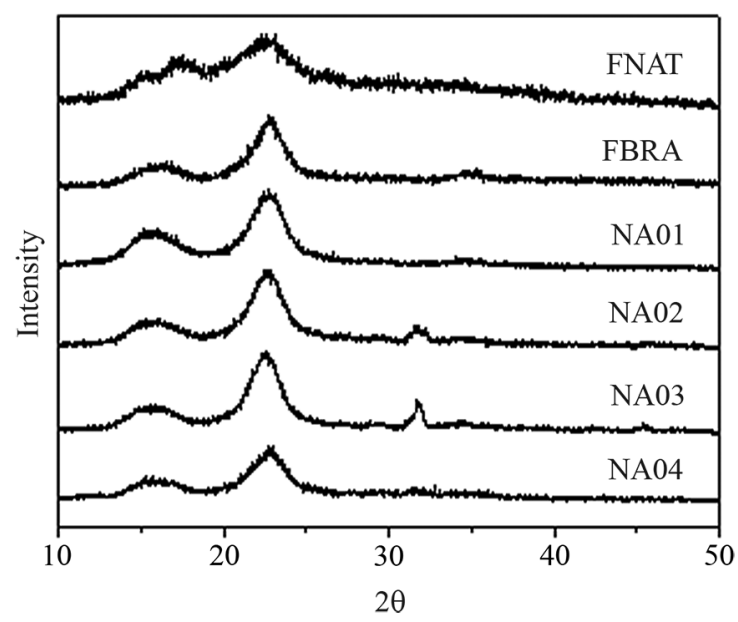

Figure 2. X-ray diffractograms of the samples.

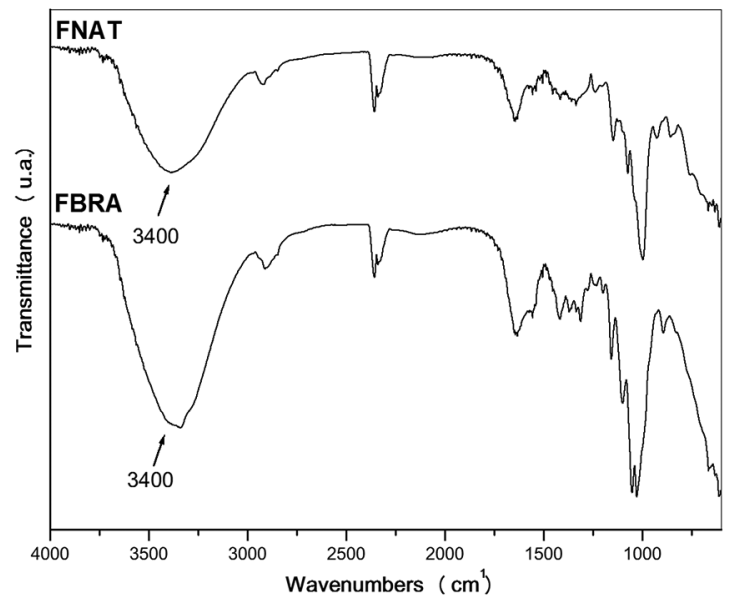

(a) hydrolysis. The highest indexes of nanowhiskers crystallinity were found for the samples NA03 and NA04, where the lower temperatures for the acid hydrolysis reaction were used.

The chemical structure of the samples was analyzed using FTIR by granulating of the sample with $\mathrm{KBr}$. The FTIR spectra of in natura and bleached fibers are shown in Figure 3 the following:

When comparing the spectra of in nature and bleached fibers, it is observed in Figure 3a, that they exhibit similar bands in the range of $3400 \mathrm{~cm}^{-1}$ regarding to the $\mathrm{OH}$ group present in the three constituents of the fibers.

In Figure 3b, the range of $700-1000\left(\mathrm{~cm}^{-1}\right)$ in the sample FNAT, regarding to the C-H group characterizing the lignin ${ }^{15}$ practically disappears when applying the bleaching. Also analyzing sample FNAT, bands of 1077-1150 $\left(\mathrm{cm}^{-1}\right)$ are attributed to the C-O-C functional group characteristic of the cellulose $\mathrm{e}^{15}$, the same assignment is made to the band in the wavelength range of $1646\left(\mathrm{~cm}^{-1}\right)$ which is also observed in the sample FBRA ${ }^{[15]}$.

The sample FBRA in Figure 3b, also showed a small lignin content in the range of $900\left(\mathrm{~cm}^{-1}\right)$. The bands of $1028\left(\mathrm{~cm}^{-1}\right)$ to $1162\left(\mathrm{~cm}^{-1}\right)$ are attributed to the cellulose ${ }^{15}$, that after the bleaching process was most evident its presence. Small

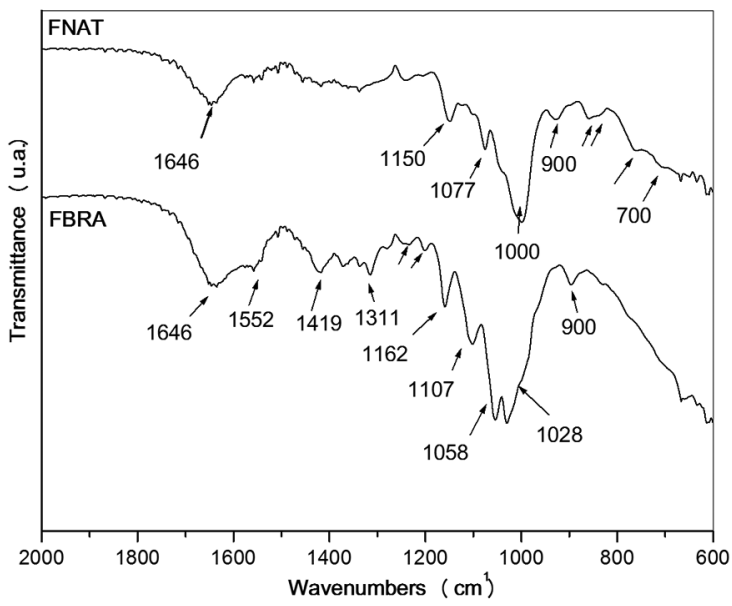

(b)

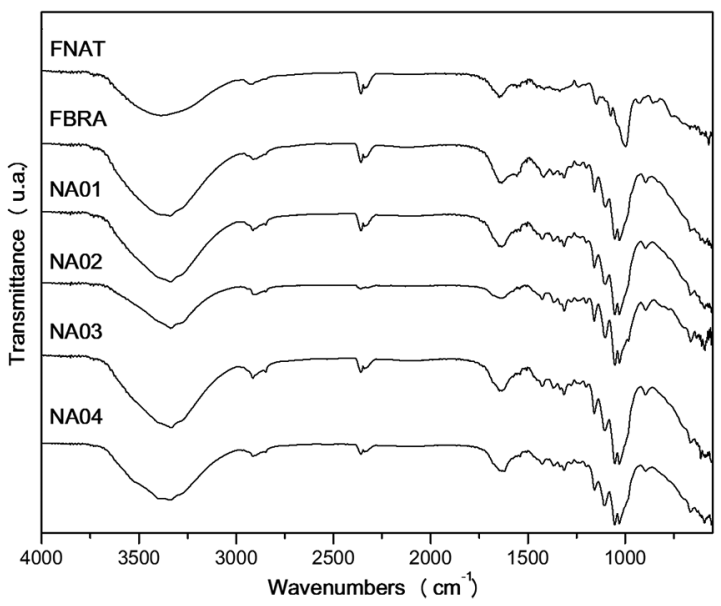

(c)

Figure 3. FTIR spectra of in nature, bleached fibers and of the nanowhiskers. 
bands between 1311 and $1552\left(\mathrm{~cm}^{-1}\right)$, were also attributed to presence of lignin.

On Figure $3 \mathrm{c}$ it is made a comparison between the samples FNAT and FBRA with obtained nanowhiskers, lignin bands are not observed, which cellulose bands predominate.

The nanowhiskers morphology obtained by the acid hydrolysis with sulfuric acid was studied by transmission electron microscopy as shown in Figure 4a-d. The micrographs show that the structures at nanometer scales in needled format, were obtained after acid hydrolysis of the bleached fibers (FBRA), confirming the positive result of the treatment used in the present study.

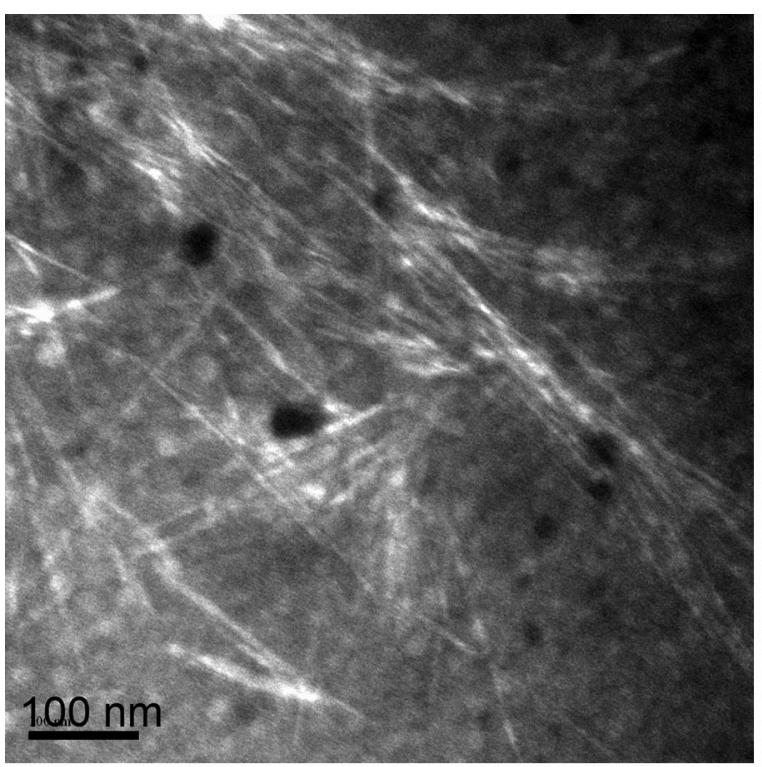

(a)

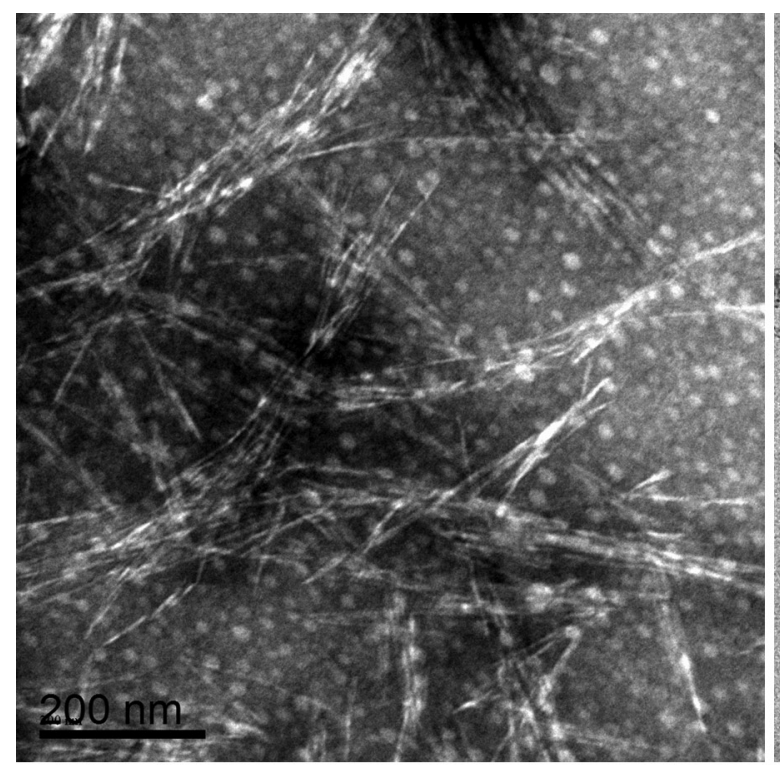

(c)
From the micrographs, the diameter and length of nanowhiskers were determined using the ImageJ software then was possible to determine the aspect ratio of the obtained samples with of the different conditions of acidic hydrolysis. The results are shown in Table 3 .

In the NA01 sample, low acid concentrations with the higher temperature gave favorable environment for the chemical extraction nanowhiskers with a higher aspect ratio, compared to the other samples. In NA03 sample, which is worked with the smallest acid concentration and lower temperature range with the highest measurement of length and diameter.

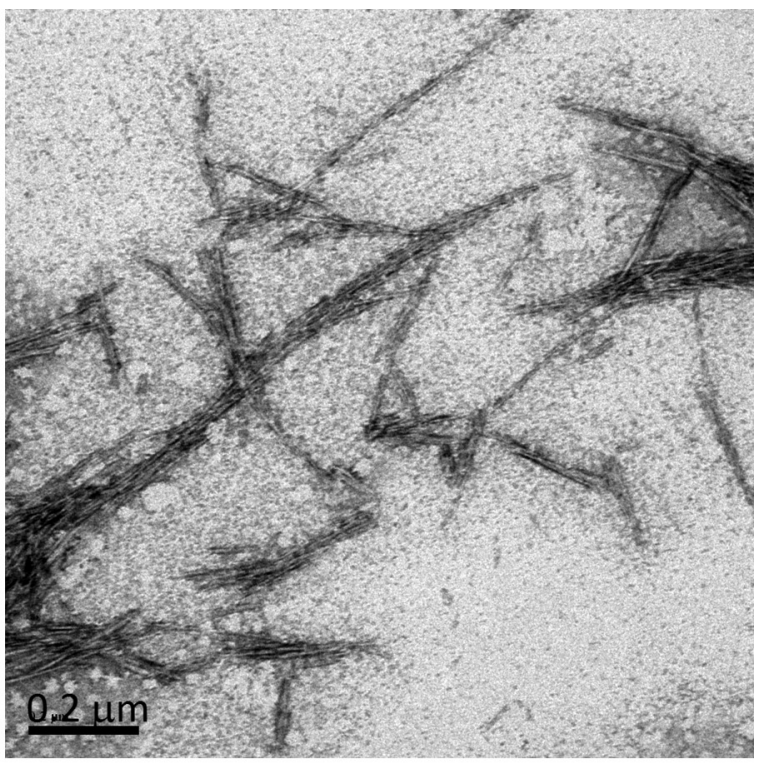

(b)

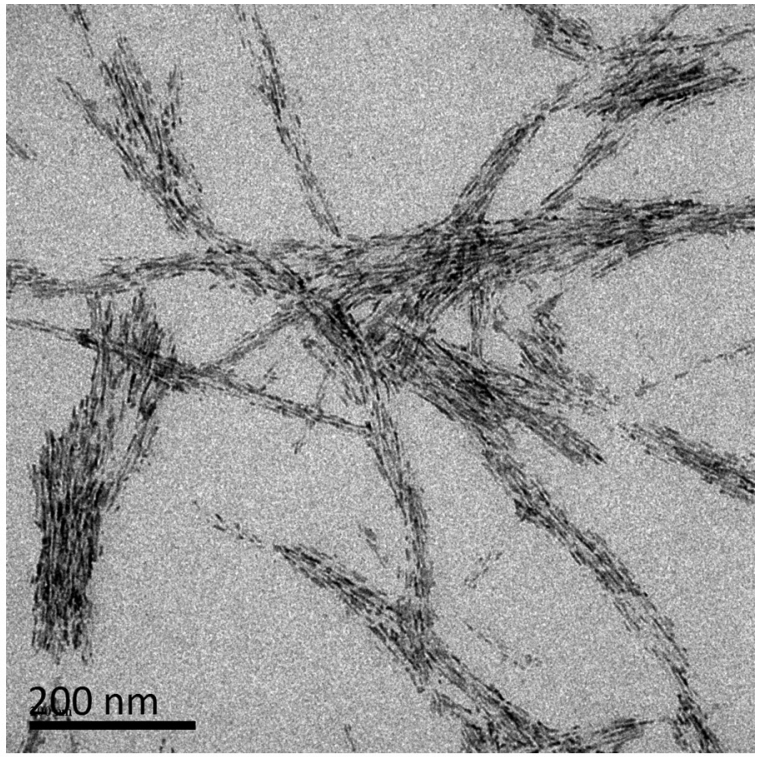

(d)

Figure 4. Transmission electron microscopy of all samples obtained. 
Table 3. Length, diameter and aspect ratio of the obtained cellulose nanowhiskers.

\begin{tabular}{cccc}
\hline Sample & Length $(\mathbf{n m})$ & $\begin{array}{c}\text { Diameter } \\
(\mathbf{n m})\end{array}$ & Aspect Ratio \\
\hline NA01 & $132+33$ & $3.1+1.5$ & 46 \\
NA02 & $121+41$ & $3.7+1.2$ & 33 \\
NA03 & $160+77$ & $4.1+1.2$ & 37 \\
NA04 & $129+45$ & $3.9+1.8$ & 35 \\
\hline
\end{tabular}

\section{Conclusions}

It was possible to obtain cellulose nanowhiskers in ways needles, fibers from bleached arrowroot, they had good thermal stability and a good crystallinity index, compared with the literature. As seen in DRX diffractograms, it appears that

\section{References}

1. Caetano CB, Callari V, Gonzaga LV, Kuskoski EM and Fett R. Atividade antioxídante e conteúdo fenólico do resíduo agroindustrial da produção de vinho. Ciências Agrárias. 2008; 29(1):93-102.

2. Catto AL, Stefani BV, Ribeiro VF and Santana RMC. Influence of coupling agent in compatibility of post-consumer HDPE in thermoplastic composites reinforced with eucalyptus fiber. Materials Research. 2014; 17(Suppl. 1):203-209. http://dx.doi. org/10.1590/S1516-14392014005000036.

3. Chianelli-Junior R, Reis JML, Cardoso JL and Castro PF. Mechanical characterization of sisal fiber-reinforced recycled HDPE composites. Materials Research. 2013; 16(6):1393-1397. http://dx.doi.org/10.1590/S1516-14392013005000128.

4. Gelfuso MV, Thomazini D, Souza JCS and Lima JJ Jr. Vibrational analysis of coconut fiber-PP composites. Materials Research. 2014; 17(2):367-372. http://dx.doi.org/10.1590/ S1516-14392013005000200.

5. Borba PM, Tedesco A and Lenz DM. Effect of reinforcement nanoparticles addition on mechanical properties of SBS/Curauá fiber composites. Materials Research. 2014; 17(2):412-419. http://dx.doi.org/10.1590/S1516-14392013005000203.

6. Gelfuso MV, Silva PVG and Thomazini D. Polypropylene matrix composites reinforced with coconut fibers. Materials Research. 2011; 14(3):360-365. http://dx.doi.org/10.1590/ S1516-14392011005000056.

7. Castro CDPC, Dias CGBT and Faria JAF. Production and evaluation of recycled polymers from açaí fibers. Materials Research. 2010; 13(2):159-163. http://dx.doi.org/10.1590/ S1516-14392010000200007.

8. Leonel M and Cereda MP. Caracterização físico-quimica de algumas tuberosas amiláceas. Ciência e Tecnologia de the type I crystal structure of cellulose fibers was preserved even after the chemical treatment process for purification, which is a positive feature.

The nanowhiskers extracted with the lowest acid concentration and higher temperature showed the best aspect ratio, when compared with other extraction conditions used in this study.

In general, the nanowhiskers obtained in this study for all four extraction conditions used feature a similarity in aspect ratio with other sources has already reported in the literature.

\section{Acknowledgements}

The authors thank CNPq, FAPESB, CAPES, FIOCRUZ and UFBA/PPEQ.

Alimentos. 2002; 22(1):65-69. http://dx.doi.org/10.1590/S010120612002000100012.

9. Pérez E, Lares M and González Z. Some characteristicsof sagu (Cannaedulis) and zulu (Marantasp) rhizomes. Journal of the Science of Food and Agriculture. 1997; 41(7):2546-2549. http:// dx.doi.org/10.1021/jf960680i.

10. Silva R, Haraguchi SK, Muniz EC and Rubira AF. Aplicações de fibras lignocelulósicas na química de polímeros e em compósitos. Química Nova. 2009; 32(3): 661-671.

11. Teodoro KBR, Teixeira EM, Corrêa AC, Campos A, Marconcini JM and Mattoso LCH. Whiskers de fibra de sisal obtidos sob diferentes condições de hidrólise ácida: efeito do tempo e da temperatura de extração. Polímeros. 2011; 21(4):280-285. http://dx.doi.org/10.1590/S0104-14282011005000048.

12. Silva JBA, Pereira FV and Druzian JI. Cassava starch-based films plasticized with sucrose and inverted sugar and reinforced with celulosenanocrystals. Journal of Food Science. 2012; 77(6): N14-N19. http://dx.doi.org/10.1111/j.1750-3841.2012.02710.x. PMid:22582979.

13. Borysiak S and Garbarczyk J. Applying the WAXS method to etimate the supermolecular structure of celulose fibres after mercerization. Fibers \& Textiles in Easterm Europe. 2003; 11:104-106.

14. Flauzino WP No, Silvério HA, Dantas NO and Pasquini D. Extraction and characterization of cellulose nanocrystals from agro-industrial residue - soy hulls. Industrial Crops and Products. 2013; 42:480-488. http://dx.doi.org/10.1016/j. indcrop.2012.06.041.

15. Morán JI, Alvarez VA, Cyras VP and Vazquez A. Extracion of cellulose and preparation of nanocellulose from sisal fibers. Cellulose. 2008; 15(1):149-159. http://dx.doi.org/10.1007/ s10570-007-9145-9. 